(2) OPEN ACCESS

\title{
Fair allocation of scarce medical resources in the time of COVID-19: what do people think?
}

\author{
Francesco Fallucchi (1) ${ }^{1}$ Marco Faravelli, ${ }^{2}$ Simone Quercia ${ }^{3}$
}

${ }^{1}$ Luxembourg Institute of SocioEconomic Research (LISER), Esch-sur-Alzette, Luxembourg ${ }^{2}$ School of Economics, The University of Queensland Saint Lucia Campus, Saint Lucia, Queensland, Australia ${ }^{3}$ Department of Economics, University of Verona, Verona, Italy

\section{Correspondence to}

Dr Francesco Fallucchi, -, Eschsur-Alzette 4366, Luxembourg; francesco.fallucchi@liser.lu

Received 30 May 2020 Revised 1 September 2020

Accepted 4 September 2020

Published Online First

12 October 2020

\section{ABSTRACT}

The COVID-19 pandemic has placed an enormous burden on health systems, and guidelines have been developed to help healthcare practitioners when resource shortage imposes the choice on who to treat. However, little is known on the public perception of these guidelines and the underlying moral principles. Here, we assess on a sample of 1033 American citizens' moral views and agreement with proposed guidelines. We find substantial heterogeneity in citizens' moral principles, often not in line with the guidelines recommendations. As the guidelines are likely to directly affect a considerable number of citizens, our results call for policy interventions to inform people on the ethical rationale behind physicians or triage committees decisions to avoid resentment and feelings of unfairness.

\section{INTRODUCTION}

The COVID-19 pandemic has now reached all world continents except Antartica. Its spread has placed an enormous and sustained burden on health systems, which has likely exacerbated the mortality rate of coronavirus SARS-CoV-2. ${ }^{1}$ Since the start of the pandemic, several noteworthy contributions have discussed important aspects of intensive care units' (henceforth ICUs) shortages. ${ }^{2-5}$ Like most allocation problems, this issue presents inherently normative questions that ethicists and physicians ought to address by developing a set of coherent and consistent rules, thus preventing healthcare practitioners to be faced 'with the terrible task of improvising decisions on whom to treat'. 2 Such guidelines are likely to directly affect a considerable number of citizens, as well as their families and relatives, throughout the pandemic and might have relevant legal implications. ${ }^{6}$ Hence, it is of paramount importance to assess their perception of the fairness of such rules. If these are not in line with people's moral views, this may create resentment and feelings of injustice that could worsen the already traumatic impact of the choices. These views could, therefore, inform policy makers and clinicians on the need to communicate appropriately the rationale behind the guidelines, in order to (partially) alleviate the above-mentioned effects. ${ }^{4}$

The purpose of this paper is to inform the debate as to whether citizens' moral principles are aligned with the proposed guidelines and recommendations. To this end, we conducted a survey among a sample of American citizens. We compare individuals' responses with the recommendations contained in ref 2 that offer a comprehensive set of guidelines for the allocation of scarce resources during COVID-19 representing a widespread consensus in the medical literature. The next section describes the survey structure and design. A methods section (section 3) describes characteristics of the sample and the statistical methodology. Section 4 presents our main results and section 5 concludes.

\section{THE SURVEY}

Our survey was conducted among a sample of 1033 American citizens using the online survey platform CloudResearch. An additional 443 started the survey but did not finish. This rate of completion (around 70\%) is in line with online studies similar to ours. Subjects were recruited from the CloudResearch panel, which is heterogeneous in many sociodemographic dimensions (see Methods). In our survey, we asked respondents to imagine a situation in which the US Federal Government is planning to publish guidelines for the allocation of ICUs during the COVID-19 pandemic. Respondents are asked which principles these guidelines should contain according to them. Respondents were informed that this was a research project and that their responses would remain anonymous. We elicited their views through the use of several hypothetical scenarios (see table 1). All scenarios contain two patients (neutrally labelled patient $\mathrm{A}$ and patient B), with different characteristics, who have been hospitalised; both patients need an ICU bed but only one is available. In all scenarios, respondents are asked which of four options they would suggest for the guidelines: admit patient A to the ICU, admit patient $\mathrm{B}$, decide randomly and admit on a first-come first-served basis. Through the use of our scenarios, we test the extent to which people's moral views are in line with the recommendations highlighted in ref 2 . Table 1 reports the wording for each scenario and the implied recommendation. Before being exposed to the scenarios, respondents had to answer four comprehension questions to ensure their understanding of the hypothetical situation. The order in which the scenarios appeared was randomised at the individual level. We believe that control questions and the randomised order of scenarios eliminate concerns about order and learning effects. After the scenarios, respondents were asked several sociodemographic questions and questions about their perceptions of the COVID-19 pandemic (see online supplemental appendix A). There we no other questions about other subjects in the survey.

\section{METHODS}

Our respondents are part of the survey panel (prime panel) of the platform CloudResearch. Respondents from this panel have been shown to be more 


\begin{tabular}{|c|c|c|}
\hline Scenario & Description & Recommendation \\
\hline S1 & $\begin{array}{l}\text { Suppose patient A and patient B due to their individual characteristics have the same remaining life expectancy. The estimated probability } \\
\text { of survival in the ICU is higher for patient A than for patient B. The guidelines should prescribe that: }\end{array}$ & Admit patient $A$ \\
\hline S2 & $\begin{array}{l}\text { Suppose patient A has higher remaining life expectancy than patient } B \text {. The estimated probability of survival in the ICU is the same for both } \\
\text { patients. The guidelines should prescribe that: }\end{array}$ & Admit patient $\mathrm{A}$ \\
\hline S3 & $\begin{array}{l}\text { Suppose patient B is chronically ill and has been in an ICU for } 2 \text { months. Patient A has contracted COVID-19. Patient B has a lower } \\
\text { probability of survival under the ICU than patient A. The guidelines should prescribe that: }\end{array}$ & Admit patient $\mathrm{A}$ \\
\hline S5 & $\begin{array}{l}\text { Suppose patient A is a nurse working in a COVID-19 hospital. Patients A and B have the same probability of survival in the ICU and the } \\
\text { same life expectancy according to their sociodemographic characteristics. The guidelines should prescribe that: }\end{array}$ & Admit patient $\mathrm{A}$ \\
\hline S6 & $\begin{array}{l}\text { Suppose patient A is a scientist working on COVID-19 vaccine. Patient B has a job unrelated to the health sector. Patients A and B have the } \\
\text { same probability of survival in the ICU and the same life expectancy according to their sociodemographic characteristics. The guidelines } \\
\text { should prescribe that: }\end{array}$ & Admit patient $\mathrm{A}$ \\
\hline
\end{tabular}

For each scenario, the last column indicates the recommendation according to the guidelines in ref 2 . The text of scenarios 3 and 4 has been slightly amended for comparability with the other scenarios (see, in particular, figure 1) with respect to the labels of patient A and patient B. For the exact wording, see questions 6 and 7 in online supplemental appendix $A$. The order has also been adjusted to be in line with the order of presentation of the results.

$\mathrm{ICU}$, intensive care unit.

heterogeneous in various aspects (eg, age, education and political attitudes) with respect to the more commonly used pool of Amazon Mechanical Turk. ${ }^{7}$ Our sample is composed by respondents from 50 different states. Respondents are highly heterogeneous in various dimensions. The majority of them are women $(60.8 \%)$, and the average age is 44.6 years $(\mathrm{SD}=16.8)$. They have a higher educational attainment than the US average according to the 2018 data of the US Census Bureau, ${ }^{8}$ as almost all of them earned at least a high school degree (98\%), and the majority of them $(52.5 \%)$ earned at least a bachelor's degree. The median household yearly income before taxes ranges between $\$ 60000$ and $\$ 70000$, in line with the national figures $(\$ 63119) .{ }^{9} \mathrm{~A}$ percentage of 17.3 of them declared to be smokers (vs $15.1 \%$ at national level). Finally, $41.6 \%$ identified themselves as Democrats, $36.6 \%$ as Republicans and $21.8 \%$ as Independents. ${ }^{10}$ The average survey completion time was $8.5 \mathrm{~min}$. Therefore, the hourly compensation for the completion averaged to \$8.82. With respect to statistical analyses, we mainly used nonparametric tests for matched observations, that is, McNemar's $\chi^{2}$ test and signrank test. ${ }^{11}$ Only in one case where we performed a between-subjects comparison, we use a test of proportions for independent observations $\left(\chi^{2}\right.$ test).

\section{RESULTS}

Figure 1 shows the percentage of responses in line with the recommendations contained in ref 2 . As it can be seen from the figure, we find high heterogeneity across scenarios. While for some scenarios responses are broadly in line with the recommendations, for others only a minority of responses is. The share of responses in line with the recommendations ranges from 5.4\% to $68.7 \%$. In what follows we summarise our main results.

\section{Result 1: maximise benefits}

Maximising benefits is considered to be the most important principle in a pandemic. ${ }^{2}$ This principle can be applied either as saving most lives or as many years of life as possible. We tested both these applications of the principle. To test the save most lives principle, in scenario 1 , we describe both patients as having the same life expectancy but patient $\mathrm{A}$ as having higher probability of survival in an ICU. To test the save the most years of life principle, in scenario 2, the probability of survival in the ICU is the same for both patients, but patient A has higher life expectancy post-treatment. Our results show that people tend to apply the maximising benefits principle significantly more often when this increases the chances of saving a life rather than when it saves more years of life in expectation $(59.6 \%$ vs $44.7 \%$, McNemar's $\chi^{2}(1)=79.58, \mathrm{p}<0.001$; signrank test, $\left.z=8.92, \mathrm{p}<0.001\right)$.

\section{Result 2: maximise benefits}

Another important implication of the maximise benefits principle is that a patient with lower probability of survival ought to be removed from an ICU when a patient with higher probability of survival needs it. ${ }^{2}$ Despite being the most rational thing to do from a utilitarian perspective, this may be considered unfair for several reasons related to well-documented behavioural phenomena. First, as resources have been already spent to cure the patient already in the ICU, respondents may be affected by the sunk cost fallacy, that is, the evidence that people commit to certain choices even when these choices are revealed to be suboptimal as time passes. ${ }^{12}{ }^{13}$ Second, a patient's incumbency may produce a sense of entitlement similar to the endowment effect in those who (perhaps subconsciously) identify with the incumbent, thus leading to the status quo bias. ${ }^{14}$ Finally, and perhaps more importantly, the emotional burden of suspending treatment may be stronger than the one of not initiating treatment, which could be caused by the perceived moral differences in omission (not treating) versus commission (suspending treatment). ${ }^{15}$ In order to test this implication of the maximise benefits principle, we included two scenarios that we administered between subjects $(n=521$ in scenario 3 and $n=511$ in scenario 4). In scenario 3, patient B, who has lower probability of survival, has been in the ICU for 2 months prior to the arrival of patient A; on the contrary, in scenario 4, the two are hospitalised at the same time. The two vignettes are otherwise identical, and for obvious reasons, we have removed the first-come firstserved option for these two scenarios. 


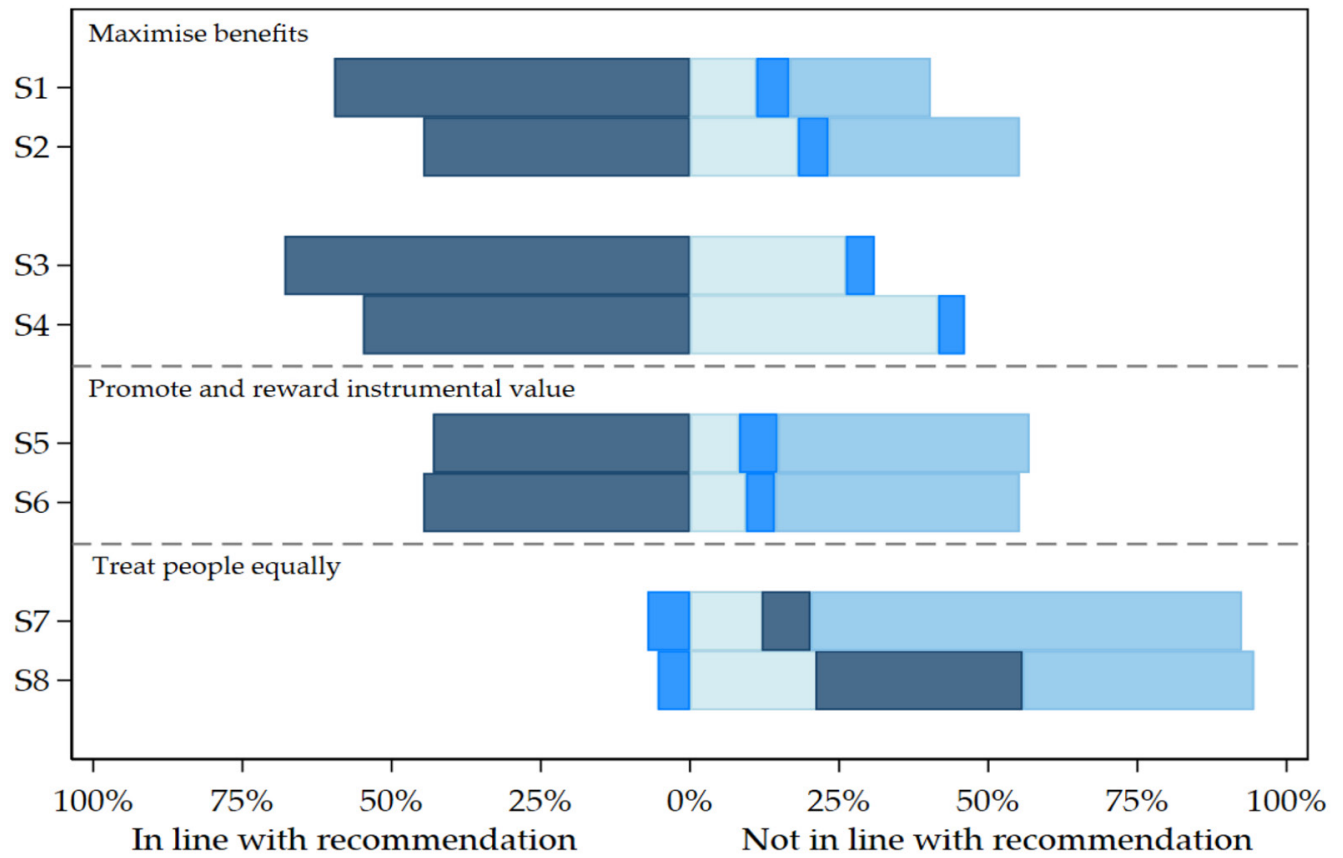

In line with recommendation

Not in line with recommendation

\begin{tabular}{|l|l|}
\hline Admit Patient A & Admit Patient B \\
Random admission & First-come first-served \\
\hline
\end{tabular}

Figure 1 Survey responses. Each bar represents the distribution of answers for each of the eight scenarios. The bars on the left-hand side represent the share of answers in line with the recommendations from the guidelines. The bars on the right-hand side represent the share of answers not in line with the recommendations.

In line with our prediction, when the two patients arrive at the same time, $68.7 \%$ agree to admit patient A, while only $54.3 \%$ do so when patient B has been in the ICU for 2 months $\left(\chi^{2}(1)=22.5\right.$, $\mathrm{p}<0.001)$.

\section{Result 3: instrumental value}

One additional recommendation is to promote and reward instrumental value, that is, to prioritise ICU admission for those patients who have contributed to the treatment of COVID-19 (ie, retrospective instrumental value) and to patients who will likely offer future contributions (ie, prospective instrumental value). ${ }^{2}$ To assess moral views for retrospective instrumental value, we created scenario 5 , in which the two patients are identical in terms of life expectancy and probability of survival, but patient $\mathrm{A}$ is a nurse who has being treating patients with COVID19. Regarding prospective instrumental value, the scenario is identical to the previous one, but patient $\mathrm{A}$, instead of being a nurse, is a scientist working on a potential vaccine to prevent COVID-19. In both cases, only around 44\% of respondents reward instrumental value, and we find no difference between prospective and retrospective instrumental value (McNemar's $\chi^{2}(1)=1.09, \mathrm{p}=0.326$; signrank test, $\left.z=1.04, \mathrm{p}=0.296\right)$ ).

\section{Result 4: treat people equally}

Recommendation 3 in ref 2 stresses that, for patients with similar prognosis, random allocation must be preferred to a first-come first-served principle, though both are application of egalitarianism. First-come first-served is typically used when scarcity is long-standing and patients can survive without the scarce resource, such as for example in the case of kidneys' transplants. When needs are urgent, however, a first-come first-served approach could unfairly benefit patients living nearer to healthcare facilities, hence resulting in a less egalitarian treatment than pure randomisation. To assess people's views on this, we included scenario 7 , in which the two patients are equal in all characteristics, as well as in prognosis. Despite most respondents choose one of the two egalitarian responses, among these the vast majority choose first-come first-served (91\%). It is worth noticing that this difference consistently occurs across all other scenarios. Among those who prefer the egalitarian options, only $7.2 \%$ choose random allocation. This may be because most cases of allocation of scarce resources are of the type where firstcome first-served is appropriate and random selection is rarely used (think, for instance, of any situation in which queuing is accepted as normal). This evidence may make first-come firstserved more salient and available due to past experience. ${ }^{16}$ This result calls for greater information to patients, and citizens, on the virtues of pure randomisation as the fairest means to insure equality (of opportunities).

\section{Result 5: treat people equally}

Another recommendation related to equality states that patients with COVID-19 and patients affected by other conditions should not be treated differently when allocating scarce resources. ${ }^{2}$ We tested this by including scenario 8 , in which the two patients have the same prognosis, but one is affected by COVID-19 and the other has pneumonia not caused by SARS-CoV-2. The percentages of those who state a preference for treating one of the two patients sum up to $55.8 \%$. This is much higher than the same answers given in scenario 7 (20.3\%), where instead an egalitarian principle is chosen by most. Most of the respondents $(34.8 \%)$ in scenario 8 suggest to treat the patient affected by COVID-19. This proportion alone is significantly higher compared with the sum of proportions of respondents choosing either option A or B in scenario 7, indicating that individuals 
tend to favour the treatment of the patient with COVID-19 in contrast to the recommendation (McNemar's $\chi^{2}(1)=62.50$, $\mathrm{p}<0.001$; signrank test, $z=7.91, \mathrm{p}<0.001)$ ).

Next, we exploit our post survey sociodemographic dataset to assess whether the results reported are heterogeneous across different strata of the population. In online supplemental appendix B, we replicate each of the results above (except result 4 in which we do not employ statistical tests) breaking down the sample for gender, education, employment status, age, political orientation and income. For all subgroups, results are in line qualitatively and in terms of significance levels with the main results reported above. We conclude that our results do not depend on the specific subgroup analysed but are stable across all subgroups.

\section{CONCLUSIONS}

Guidelines for the allocation of scarce resources during the COVID-19 pandemic are essential and can guarantee a fair and consistent allocation across cases. We have shown, through survey results, that these ethically sensible recommendations do not always reflect the views of citizens. We found considerable heterogeneity in people's moral judgements, and we believe this heterogeneity must be addressed by (better) informing citizens regarding the rationale behind each principle. We hope that this evidence may inform policy makers, as well as healthcare practitioners, of the need to provide an effective communication to citizens and patients, respectively, in order to avoid decision rules that may otherwise be perceived as arbitrary or unfair.

Contributors All authors contributed equally to this article.

Funding FF and SQ acknowledge the support of the Luxembourg National Research Fund (FNR COVID-19 Fast-track Grant 14715638- E.HAG).

Competing interests None declared.

Patient consent for publication Not required.

Ethics approval The project received ethics approval by the LISER Research Ethics Committee with official communication on 5 May by its Chair, Professor Axel Gosseries (UCL).

Provenance and peer review Not commissioned; externally peer reviewed.
Data availability statement Data are available upon request.

Open access This is an open access article distributed in accordance with the Creative Commons Attribution Non Commercial (CC BY-NC 4.0) license, which permits others to distribute, remix, adapt, build upon this work non-commercially, and license their derivative works on different terms, provided the original work is properly cited, appropriate credit is given, any changes made indicated, and the use is non-commercial. See: http://creativecommons.org/licenses/by-nc/4.0/.

\section{ORCID ID}

Francesco Fallucchi http://orcid.org/0000-0001-5502-4358

\section{REFERENCES}

1 Ji Y, Ma Z, Peppelenbosch MP, et al. Potential association between COVID-19 mortality and health-care resource availability. Lancet Glob Health 2020;8(4):e480.

2 Emanuel EJ, Persad G, Upshur R, et al. Fair allocation of scarce medical resources in the time of Covid-19. N Eng/ J Med 2020;382(21):2049-55.

3 Mannelli C. Whose life to save? Scarce resources allocation in the COVID-19 outbreak. J Med Ethics 2020;46(6):364-6.

4 Truog RD, Mitchell C, Daley GQ. The toughest triage-allocating ventilators in a pandemic. N Engl J Med 2020;382(21):1973-5.

5 White DB, Lo B. A framework for rationing ventilators and critical care beds during the COVID-19 pandemic. JAMA 2020;323(18):1773-4.

6 Liddell K, Skopek JM, Palmer S, et al. Who gets the ventilator? Important legal rights in a pandemic. J Med Ethics 2020;46(7):421-6.

7 Chandler J, Rosenzweig C, Moss AJ, et al. Online panels in social science research: Expanding sampling methods beyond Mechanical Turk. Behav Res Methods 2019;51(5):2022-38.

8 Census.gov. Educational Attainment in the United States: 2018. Available: https:// www.census.gov/data/tables/2018/demo/education-attainment/cps-detailed-tables. html [Accessed May 2020].

9 U.S. Census Bureau. Real Median Household Income in the United States [MEHOINUSA672N]. Available: https://fred.stlouisfed.org/series/MEHOINUSA672N [Accessed May 2020].

10 The latest Gallup figures report an equal split among the three options. Available: https://news.gallup.com/poll/15370/party-affiliation.aspx [Accessed May 2020]

11 Siegel S, Castellan Jr NJ. Nonparametric statistics for the behavioral sciences. McGraw-Hill Publishing, 1981.

12 Arkes HR, Blumer C. The psychology of sunk cost. Organ Behav Hum Decis Process 1985:35(1):124-40.

13 Heath C. Escalation and de-escalation of commitment in response to sunk costs: the role of budgeting in mental accounting. Organ Behav Hum Decis Process 1995;62(1):38-54.

14 Kahneman D, Knetsch JL, Thaler RH. Anomalies: the Endowment effect, loss aversion, and status quo bias. J Econ Perspect 1991;5(1):193-206.

15 Spranca M, Minsk E, Baron J. Omission and commission in judgment and choice. J Exp Soc Psychol 1991;27(1):76-105.

16 Tversky A, Kahneman D. Availability: a heuristic for judging frequency and probability. Cogn Psychol 1973;5(2):207-32. 